02,01

\title{
Исследование СВЧ-свойств высокотемпературных джозефсоновских контактов на сапфировой бикристалической подложке
}

\author{
(C) Е.Е. Пестов ${ }^{1,2}$, Д.В. Мастеров ${ }^{1}$, А.Е. Парафин ${ }^{1}$, С.А. Павлов ${ }^{1}$, А.М. Клушин ${ }^{1}$ \\ ${ }^{1}$ Институт фоизики микроструктур РАН, \\ Нижний Новгород, Россия \\ ${ }^{2}$ Нижегородский государственный университет им. Н.И. Лобачевского, \\ Нижний Новгород, Россия \\ E-mail: pestov@ipmras.ru
}

Исследованы ВТСП бикристаллические переходы шириной до $50 \mu \mathrm{m}$ на сапфировых подложках. Измерены зависимости величины критического тока от температуры и внешнего магнитного поля для таких контактов. При температуре $77 \mathrm{~K}$ получены ступени Шапиро на BAX с напряжением порядка $150 \mu \mathrm{V}$ при облучении на частоте $73 \mathrm{GHz}$ джозефсоновского перехода на сапфировой подложке. Проанализирована возможность использования таких контактов в эталонах напряжения при температуре $77 \mathrm{~K}$ в области СВЧ и терагерцовых частот.

Авторы благодарят за частичную поддержку гранты РФФИ № 15-02-05793, № 15-42-02469 (р-поволжье), № 16-02-00727, а также грант РНФ № 15-12-10020. В работе использовано оборудование ЦКП „Физика и технология микро- и наноструктур“.

DOI: $10.21883 /$ FTT.2017.11.45047.06k

\section{1. Введение}

Высокочувствительные микроволновые приемники необходимы для мониторинга атмосферы, биомедицинских исследований, контроля безопасности. Обычные полупроводниковые детекторы ограничены по частоте и чувствительности. Стандартные Фурье-спектрометры, генераторы гетеродина на основе ламп обратной волны и лазеров дальнего ИК-диапазона громозки, сложны в управлении и дорогостоящи. Альтернативой всем этим устройствам могут стать сверхпроводниковые устройства, такие как, джозефсоновские прямые и селективные детекторы, СИС-смесители с джозефсоновскими генераторами гетеродина, гильберт-спектрометры, СКВИД-датчики, усилители, эталоны напряжения [1-3]. В отличие от традиционных ниобиевых устройств, с рабочей температурой в районе $4 \mathrm{~K}$, высокотемпературные сверхпроводники (ВТСП) позволяют работать при температуре жидкого азота $77 \mathrm{~K}$, в том числе с использованием простых и дешевых криоохладителей замкнутого цикла [4].

Одним из перспективных применений высокотемпературных сверхпроводников является эталон напряжения на основе цепочек из джозефсоновских контактов $[4,5]$. Для создания микросхем для этих целей на современном этапе применяется технология, основанная на использовании бикристаллических контактов, которая позволяет изготавливать из них цепочки на основе высокотемпературных сверхпроводников с требуемыми параметрами и воспроизводимым образом. Основные этапы этой технологии включают в себя выбор подходящей бикристаллической подложки, выращивание на этой подложке эпитаксиальной тонкой пленки высокотемпературного сверхпроводника, формирование рисунка схемы метода- ми фотолитографии и ионного травления. В настоящее время для получения высококачественных бикристаллических контактов широко используются подложки из окиси иттрия, стабилизированной цирконием (YSZ) [4,5]. Однако недостатками этих подложек являются высокие СВЧ-потери и их низкая теплопроводность. В то же время, ВТСП-бикристаллические переходы на сапфировых подложках [6-10] представляются перспективными кандидатами для использования в эталонах напряжения, поскольку сапфир имеет низкое поглощение на СВЧ и хорошие тепловые характеристики. Поэтому создание микросхем на основе сапфировых подложек может привести к созданию новых эталонов, что расширит область применения этих приборов в квантовой метрологии и радиоизмерительной технике.

Формирование топологии является критически важным этапом при изготовлении планарных структур на основе пленок высокотемпературного сверхпроводника $\mathrm{YBa}_{2} \mathrm{Cu}_{3} \mathrm{O}_{7-d}$ (YBCO), который существенно влияет на их конечные параметры. Это обусловлено очень высокой чувствительностью свойств пленок ҮВСО к внешним воздействиям. При традиционном методе получения структур на основе пленок ҮВСО в готовой пленке химическим или ионным травлением [11,12], или же ионной имплантацией создаются изолирующие области [13-15], разделяющие сверхпроводящие элементы. В настоящей работе был использован альтернативный метод формирования топологии, в котором напыление пленки ҮВСО является завершающим этапом изготовления структуры. На подложках формировалась специальная „задающая“ маска, так что при стандартном напылении пленки YВСО на такую подложку в модифицированных областях рос слой изолятора, а в немодифицированных - сверхпроводящая пленка. В ре- 
зультате формировалась заданная топология планарной сверхпроводящей структуры.

Методом предварительной модификации поверхности сапфировой подложки были изготовлены ВТСП-бикристаллические переходы шириной 3,10 и $50 \mu \mathrm{m}$ на основе эпитаксиальных пленок $\mathrm{YBa}_{2} \mathrm{Cu}_{3} \mathrm{O}_{7-d}$ (YBCO). Транспортные и СВЧ-свойства высокотемпературных джозефсоновских контактов на сапфировой бикристалической подложке исследованы на частотах 19 и $75 \mathrm{GHz}$ при температуре кипения жидкого азота для их использования в эталонах напряжения.

\section{2. Технология изготовления}

Для изготовления бикристаллических переходов шириной 3,10 , и $50 \mu \mathrm{m}$ был использован метод, основанный на предварительной модификации сапфировой подложки [16]. В данном методе поверхность подложки, пригодной для эпитаксиального роста пленок YВСО, модифицируется путем формирования на ней специальной „задающей“ маски, которая определяет топологию создаваемой структуры непосредственно в процессе роста пленки ҮВСО. В окнах маски, где открыта исходная поверхность подложки, во время напыления YВCO формируются сверхпроводящие элементы, а в других частях подложки, покрытой маскирующей пленкой, - изолирующие области. Важно отметить, что при формировании топологии рисунка таким способом края сверхпроводящих элементов не подвергаются деградирующему воздействию, как это происходит при травлении или ионной имплантации.

В качестве материала задающей маски в работе была использована аморфная пленка оксида церия $\mathrm{CeO}_{2}$. Порядок изготовления структуры следующий. Сначала на сапфировой подложке формировалась маска из фоторезиста, после чего при комнатной температуре на подложку напылялся оксид церия. Затем фоторезист вместе с напыленной на него пленкой оксида церия удалялся с подложки в ацетоне в ультразвуковой ванне. Таким образом, на подложке создавалась маска из аморфной пленки оксида церия, в которой вскрыты окна для последующего формирования в них сверхпроводящих элементов. После изготовления задающей маски на подложку осаждался оксид церия $\mathrm{CeO}_{2}$ при температуре $T_{d}=900^{\circ} \mathrm{C}$, и в завершение выращивалась пленка ҮВСО при температуре $T_{d}=800^{\circ} \mathrm{C}$. В результате в окнах, на подслое эпитаксиального оксида церия формировались сверхпроводящие элементы заданного рисунка, а между ними, там где подложка была покрыта пленкой аморфного оксида церия, - диэлектрические области. Оксид церия наносился распылением керамической мишени состава $\mathrm{CeO}_{2}$ излучением эксимерного лазера LPX $200(\lambda=248 \mathrm{~nm})$ в атмосфере кислорода при давлении $P=20$ Ра. Пленки YВСО осаждались методом магнетронного напыления в стандартных условиях для эпитаксиального роста YBCO [17] при температуре подложки $T_{d}=800-850^{\circ} \mathrm{C}$ и давлении газовой смеси $\operatorname{Ar}(50 \%) / \mathrm{O}_{2} P=75 \mathrm{~Pa}$.

\section{3. СВЧ-зонд для облучения бикристаллических контактов}

Для исследования СВЧ-свойств джозефсоновских контактов в двух частотных диапазонах были использованы два измерительных зонда (рис. 1). Основу первого зонда составляет круглый волновод длиной $l=65 \mathrm{~cm}$, который в выбранном диапазоне частот $70-76 \mathrm{GHz}$ является сверхразмерным (рис. 1, $a$ и рис. 1, $b$ ) [5]. Оба конца волновода заканчиваются переходами на стандартный волновод WR12. К концу волновода, который погружается в сосуд Дьюара, подсоединен круглый рупор. После рупора размещается образец с джозефсоновскими контактами, поверхность которого ориентирована параллельно плоскости апертуры рупора. За образцом также может размещаться металлическое зеркало, позволяющее улучшить согласование внешнего излучения с джозефсоновской структурой. Конструкция зонда позволяет изменять взаимное положение рупора, образца и зеркала. Поляризация электрического поля выбирается с помощью вращения сверхразмерного волновода. Ранее было установлено, что максимальное значение первой ступени Шапиро наблюдается в случае, когда электрическое поле направлено вдоль бикристал-
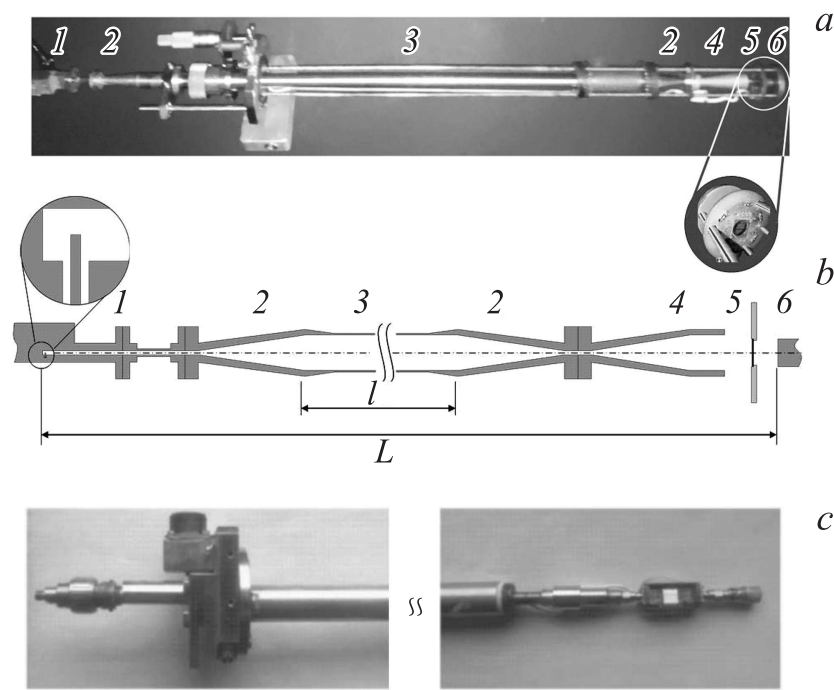

$c$

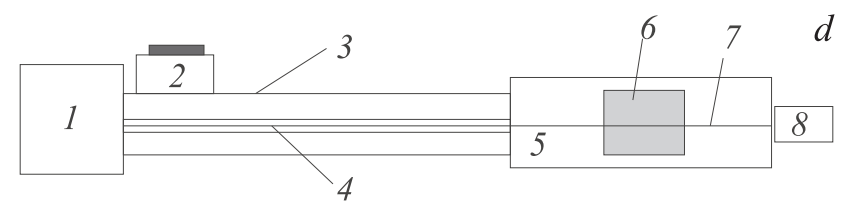

Рис. 1. Внешний вид $(a)$ и блок-схема $(b)$ измерительного зонда на диапазон частот 70-76 GHz: 1 - умножитель, 2 - волноводные переходы, 3 - круглый волновод, 4 - круглый рупор, 5 - образец на текстолитовом держателе, 6 зеркало. Внешний вид $(c)$ и блок-схема $(d)$ измерительного зонда на диапазон частот 9-20 GHz: 1 - СВЧ-генератор, 2 - разъем проводов для измерения ВАХ, 3 - труба из нержавеющей стали, 4 - коаксиальный кабель, 5 - медный столик, 6 - образец, 7 - медный провод, $8-$ нагрузка. 
лической границы [18]. Поскольку масштаб изменения электрического поля порядка размера апертуры рупора, электрическое поле изменяется слабо на характерных масштабах структуры. Поэтому с помощью этого метода настройки удается довольно легко найти оптимальное положение плоскости поляризации. К противоположному концу сверхразмерного волновода подключается через волноводный переход твердотельный умножитель на 8 , на который подается сигнал от синтезатора частот в диапазоне от 8.5 до $9.5 \mathrm{GHz}$. Так как критическая частота волноводного перехода WR12 равна $50 \mathrm{GHz}$, сигнал на более низких частотах не распространяется через зонд. Снаружи зонд герметично закрывается металлическим корпусом, а также экраном из пермаллоя для защиты микросхемы от внешних магнитных полей. Перед измерениями внутрь корпуса напускается гелий, который обеспечивает эффективное охлаждение микросхемы при погружении зонда в жидкий азот, а также защищает образец от воздействия влаги при отогреве.

Во втором случае источником СВЧ-сигнала в диапазоне частот 9-20 GHz являлся СВЧ-генератор (рис. 1, $c$, рис. $1, d)$. Далее СВЧ-сигнал распространялся к образцу по коаксиальному кабелю. Исследуемый образец размещается на медном столике. Для облучения джозефсоновских контактов используется медный провод диаметром $140 \mu \mathrm{m}$, который является продолжением внутреннего проводника коаксиального кабеля. К концу линии подсоединяется нагрузка $50 \Omega$ для лучшего согласования СВЧ-тракта. Корпус зонда состоит из трубы из нержавеющей стали. Для подачи токов смещения и измерения BAX-микросхемы имеется несколько пар медных проводов. Измерения как в первом, так и во втором случае проходят в сосуде Дьюара с жидким азотом в диапазоне температур от 65 до $90 \mathrm{~K}$.

\section{4. Транспортные и СВЧ-свойства джозефсоновских контактов}

С помощью экспериментальной установки, детально описанной выше, были проведены исследования транспортных и СВЧ-свойств джозефсоновских контактов шириной 3,10 и $50 \mu \mathrm{m}$ выполненных на сапфировой подложке. Было установлено, что переходы шириной $50 \mu \mathrm{m}$ обладают наилучшими сверхпроводящими характеристиками. На рис. 2 показана температурная зависимость критического тока джозефсоновского контакта $I_{c}(T)$ шириной $50 \mu \mathrm{m}$. Из рис. 2 видно, что полученный джозефсоновский контакт имеет высокое качество. В частности, температура перехода таких контактов в сверхпроводящее состояние составила около $87 \mathrm{~K}$, их критический ток $I_{c}$ был равен $0.85 \mathrm{~mA}$ при температуре $77 \mathrm{~K}$. Из рис. 2 также видно, что при температурах близких к $T_{c}$ температурная зависимость критического тока $I_{c}(T)$ имеет линейную за-

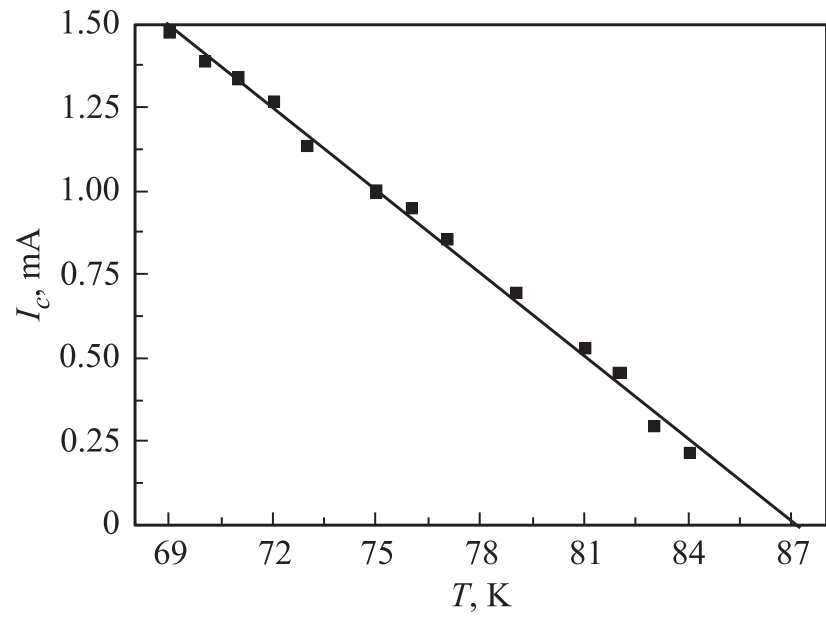

Рис. 2. Температурная зависимость критического тока джозефсоновского контакта $I_{c}(T)$ изготовленного на сапфировой бикристаллической подложке. Сплошной кривой показана линейная аппроксимация $I_{c}(T)$ в рамках теории Амбегаокара-Баратова.

висимость. Следует отметить, что бикристаллический контакт имеет углы разориентации кристаллографических осей ВТСП-электродов 12 и $-12^{\circ}$ относительно нормали границы. Поэтому, как было показано в работе [9], при симметричном задании транспортного тока через переход и зеркально симметричной бикристаллической границе ток-фазовая зависимость близка к синусоидальной из-за двойникования ВТСП-электродов, образующих переход. В этом случае, при температурах близких с критической и малых углов разориентации бикристаллической границы ВТСП-контакт может быть описан с помощью туннельной модели [19]. На рис. 2 показана аппроксимация $I_{c}(T)$ при температурах близких к $T_{c}$ с помощью теории Амбегаокара-Баратова для перехода сверхпроводник-изолятор-сверхпроводник [20] при значениях параметров: $I_{c}(69 K)=1.5 \mathrm{~mA}$, $R_{n}=0.14 \Omega$ и $2 \Delta_{0} / k T_{c}=1$. Следует отметить, что пониженное значение величины сверхпроводящей щели $\Delta_{0}=4 \mathrm{meV}\left(2 \Delta_{0} / k T_{c} \cong 1\right)$, полученное из аппроксимации $I_{c}(T)$, может быть обусловлено, по нашему мнению, двойникованием пленки ВТСП в области джозефсоновского контакта.

На рис. 3 показана зависимость критического тока от постоянного магнитного поля $I_{c}(H)$ для джозефсоновского контакта на сапфировой бикристаллической подложке при температуре $85 \mathrm{~K}$. На рис. 3 также показана расчетная зависимость $I_{c}(H)$, полученная в простейшей модели для туннельного контакта [20]

$$
I_{c}(H)=I_{c}(0) \frac{\sin \left(\pi \frac{\Phi}{\Phi_{0}}\right)}{\pi \frac{\Phi}{\Phi_{0}}},
$$

где $-\Phi \sim H-$ поток пронизывающий джозефсоновский контакт, $\Phi_{0}-$ квант магнитного потока. Как 


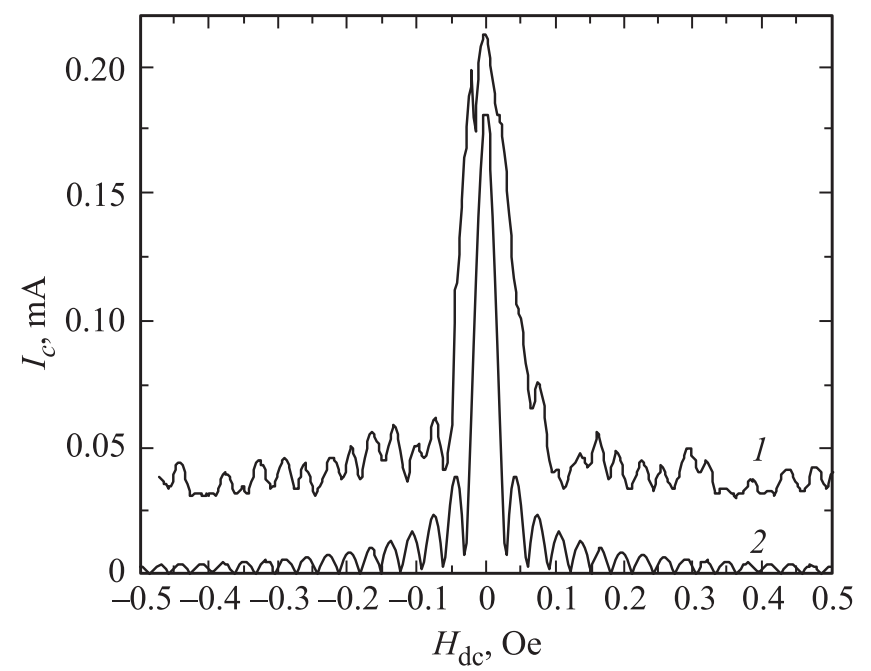

Рис. 3. Зависимость критического тока от постоянного магнитного поля $I_{c}(H)$ для джозефсоновского контакта шириной $50 \mu \mathrm{m}$ на сапфировой бикристаллической подложке измеренная при температуре $85 \mathrm{~K}-(1)$ (сдвинута вверх на $0.03 \mathrm{~mA}$ ) и $(2)$ - теоретическая зависимость $I_{c}(H)$.

видно рис. 3 формула (1) качественно описывает экспериментальную кривую $I_{c}(H)$, однако форма экспериментальной кривой отличается от теоретической зависимости. Это отличие связано с тем, что контакт является широким, т.е. его ширина $w=50 \mu \mathrm{m}$ много больше джозефсоновской глубины проникновения $\lambda_{\mathrm{J}}$. Джозефсоновскую глубину проникновения $\lambda_{\mathrm{J}}$ контакта можно оценить, исходя из формулы [20]

$$
\lambda_{\mathrm{J}}=\left(\frac{\Phi_{0}}{4 \pi j_{c} \mu_{0} \lambda}\right)^{\frac{1}{2}}
$$

где $\lambda$ - лондоновская глубина проникновения в сверхпроводник, $j_{c}$ - плотность критического тока контакта. Подставляя $\lambda=200 \mathrm{~nm}, j_{c}(85 K)=3 \cdot 10^{3} \mathrm{~A} / \mathrm{cm}^{2}$, получаем значение величины $\lambda_{\mathrm{J}}$ равным примерно $6 \mu \mathrm{m}$. В этом случае, форма кривой $I_{c}(H)$ может иметь более сложный вид из-за неоднородного распределения тока в контакте [20].

На рис. 4 показана зависимость высоты нулевой, первой и второй ступени от нормированной мощности для джозефсоновского контакта, полученная на частоте $9.668 \mathrm{GHz}$ при температуре $77 \mathrm{~K}$. Как видно из рис. 4, джозефсоновский переход качественно описывается в рамках резистивно - шунтированной модели [21]. А именно, максимум первой ступени Шапиро наблюдается вблизи минимума амплитуд нулевой и второй ступени Шапиро. В то же время, амплитуда первой и второй ступеней Шапиро наблюдаемых в эксперименте по величине меньше теоретических значений. Также из полученных зависимостей, используя зануления $n$-ной ступени [21], можно определить характерную частоту джозефсоновского контакта $f_{c}=57 \mathrm{GHz}$.
На рис. 5 показана ВАХ джозефсоновского контакта шириной $50 \mu \mathrm{m}$, изготовленного на сапфировой бикристаллической подложке без облучения и при облучении сигналом на частоте $f=72.816 \mathrm{GHz}$ при температуре 77 К. Из рисунка видно, что при воздействии излучения на ВАХ наблюдается первая ступенька Шапиро с размахом по току $\Delta I_{1} \cong 0.8 \mathrm{~mA}\left(\Delta I_{1} / I_{c} \cong 0.9\right)$ при напряжении порядка $150 \mu \mathrm{V}$ и температуре образца $77 \mathrm{~K}$. Следует отметить, что высота этой ступеньки имеет

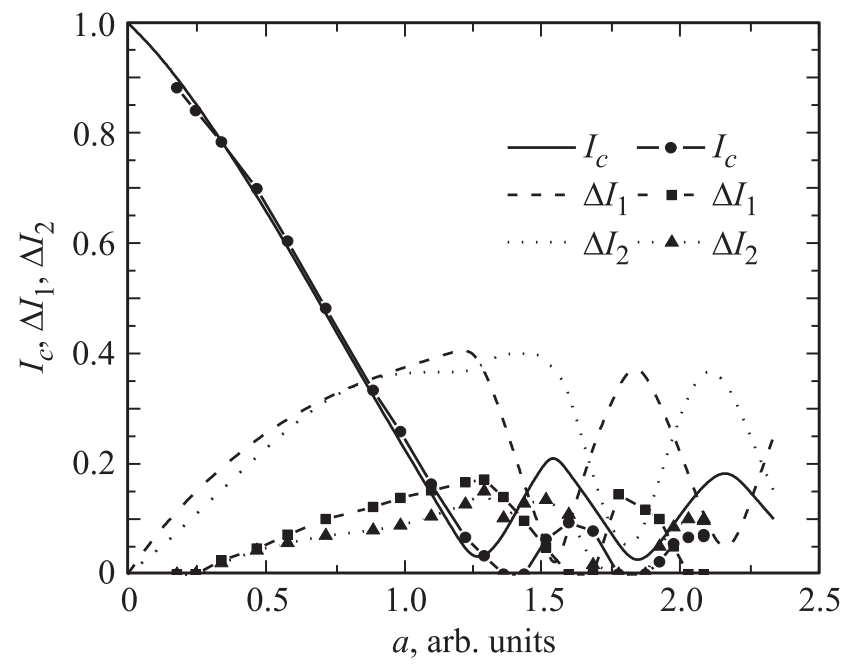

Рис. 4. Зависимость критического тока и нормированной высоты первой и второй ступени от нормированного СВЧ-тока для джозефсоновского контакта на сапфировой бикристаллической подложке (символы). Также показаны теоретические кривые зависимости критического тока и высоты первой и второй ступени от нормированного СВЧ-тока, рассчитанные в рамках резистивно-шунтированной модели $\left(I_{c}=0.6 \mathrm{~mA}, R_{n}=0.14 \Omega\right.$, $f=9.668 \mathrm{GHz})$.

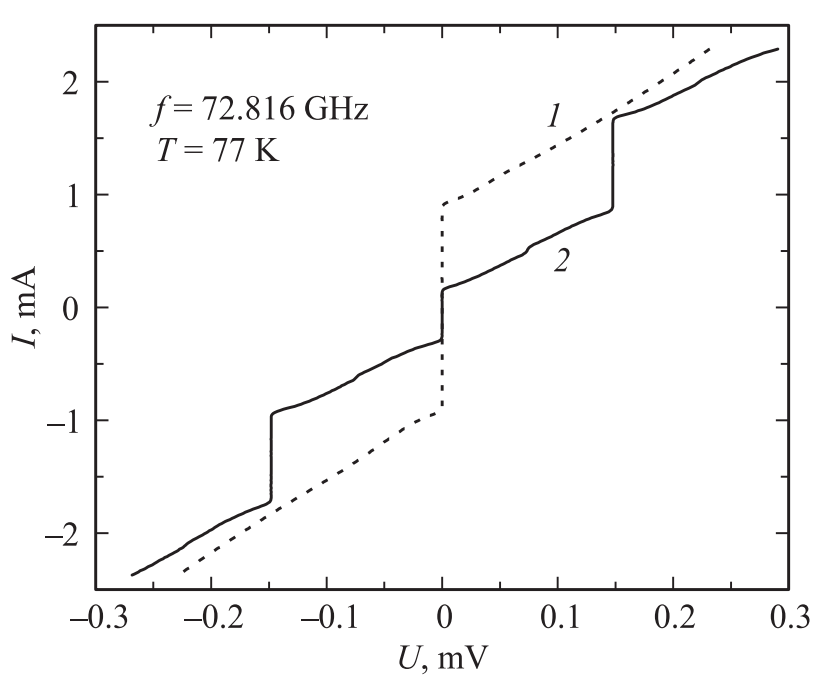

Рис. 5. ВАХ джозефсоновского контакта шириной $50 \mu \mathrm{m}$ изготовленного на сапфировой бикристаллической подложке без облучения (1) и при облучении (2) сигналом на частоте $f=72.816 \mathrm{GHz}$ при температуре $77 \mathrm{~K}$. 


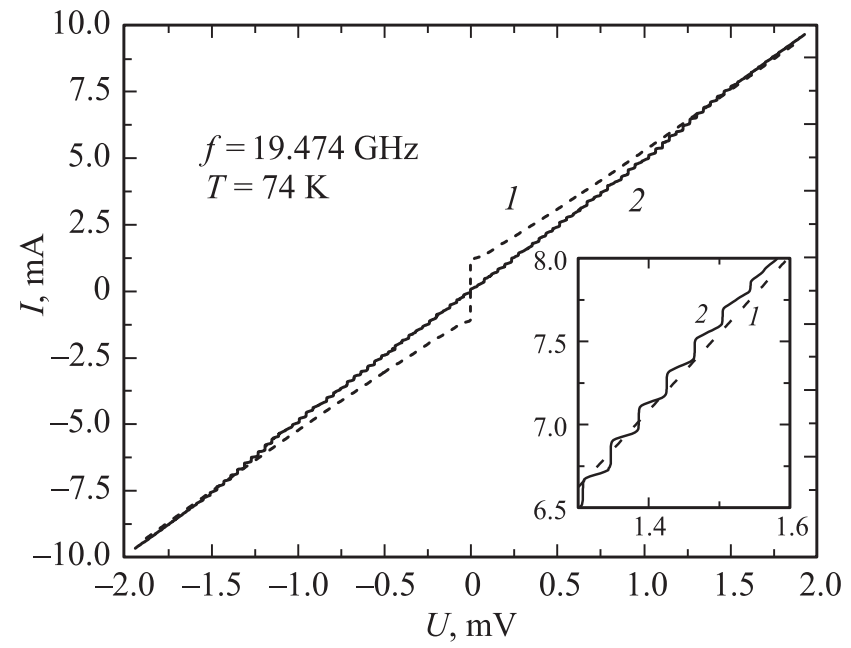

Рис. 6. $\mathrm{BAX}$ джозефсоновского контакта шириной $50 \mu \mathrm{m}$ изготовленного на сапфировой бикристаллической подложке без облучения (1) и при облучении (2) сигналом на частоте $f=19.474 \mathrm{GHz}$ при температуре $74 \mathrm{~K}$.

довольно большую амплитуду по току. Характерное напряжение контакта $V_{c} \cong 120 \mu \mathrm{V}$ для получения ступени тока при облучении контакта на этой частоте. Кроме этого, на ВАХ также наблюдается субгармоническая ступенька Шапиро. Как было отмечено выше, спектр облучающего сигнала не содержит компоненты на этой частоте. Поэтому появление этой ступеньки на ВАХ связано, по видимому, с взаимодействием СВЧ-излучения с джозефсоновским контактом. Как известно из литературы, наличие субгармонической компоненты может быть обусловлено различными механизмами $[22,23]$, включая несинусоидальную ток-фазовую зависимость [9,24]. Однако следует заметить, что высота половинной ступени на BAX для бикристаллических контактов на сапфировой подложке значительно меньше высоты первой ступени Шапиро при частоте СВЧ-облучения $72 \mathrm{GHz}$. Этот факт свидетельствует о хорошем согласии с резистивношунтированной моделью [21] и высоком качестве бикристаллического джозефсоновского контакта.

На рис. 6 показана BAX джозефсоновского контакта без облучения и при облучении сигналом на частоте $f=19.474 \mathrm{GHz}$ при температуре $74 \mathrm{~K}$. Как видно из рис. 6 ступеньки Шапиро на ВАХ наблюдаются вплоть до напряжения $1.6 \mathrm{mV}(\sim 1 \mathrm{THz})$. Следует отметить, что наличие высоких ступеней на BAX реального контакта никоим образом еще не означает наличия реального эффекта Джозефсона на частотах, соответствующих этим ступеням [21]. Это может быть связано, например, с зависимостью критического тока от частоты воздействия. В то же время, их наличие свидетельствует о малом поглощении тока на $\mathrm{THz}$ частотах в сапфировой подложке и ее хороших тепловых характеристиках. Таким образом, контакты, изготовленные на сапфировой подложке, являются перспективными кандидатами как в СВЧ, так и в терагерцовом диапазоне частот для построения эталона напряжения. Хотя для их реального применения в области терагерцовых частот необходимы дополнительные исследования таких структур.

\section{5. Заключение}

Изготовлены ВТСП бикристаллические переходы шириной до $50 \mu \mathrm{m}$ методом предварительной модификации поверхности сапфировой подложки. Оценены параметры полученных джозефсоновских переходов из транспортных и СВЧ измерений. При температуре $77 \mathrm{~K}$ получены ступени на ВАХ размахом по току $\Delta I_{1} / I_{c} \cong 0.9$ и напряжением порядка $150 \mu \mathrm{V}$ при облучении на частоте $73 \mathrm{GHz}$. Рассмотрена возможность использования таких контактов в эталонах напряжения при температуре кипения жидкого азота в области СВЧ и терагерцовых частот.

\section{Список литературы}

[1] Yu.Ya. Divin, O.Yu. Polansky, A.Ya. Shulman. IEEE Trans. Magn. 19, 613 (1983).

[2] Zmuidzinas J., Richards. Proc. IEEE. 92, 1597 (2004).

[3] J. Kohlmann. Quantum Standards for Voltage. In: Applied Superconductivity: Handbook on Devices and Applications / Ed. P. Seidel. Wiley-VCH (2015). P. 807-827.

[4] Е.Е. Пестов, М.Ю. Левичев, А.М. Клушин. Поверхность 3, 41 (2016).

[5] А.М. Клушин, Е.Е. Пестов, М.А. Галин, М.Ю. Левичев. ФTT 58, 2121 (2016).

[6] М. Тарасов, Л. Кузьмин, Е. Степанцов. Письма в ЖЭТФ 79, 356 (2004).

[7] М. Тарасов, Е. Степанцов, А. Калабухов. Письма в ЖЭТФ 86, 828 (2007).

[8] E. Stepantsov, M. Tarasov, A. Kalaboukhov. J. Appl. Phys. 96, 3357 (2004).

[9] Г.А. Овсянников, И.В. Борисенко, К.И. Констанинян, А.Д. Маштаков, Е.А. Степанцов. Письма в ЖТФ 25, 65, (1999).

[10] K.Y. Constantinian, G.A. Ovsyannikov, I.V. Borisenko, P. Yagoubov. Physica C 372-376, 420 (2002).

[11] M. Malnou, C. Feuillet-Palma, C. Ulysse, G. Faini, P. Febvre, M. Sirena, L. Olanier, J. Lesueur, N. Bergea. J. Appl. Phys. 116, 074505 (2014).

[12] J.V. Obona, M. Chromik, M. Spankova, Z. Oszi, I. Kostic. Physica C 435, 37 (2006).

[13] J.D. Pedarnig, M.A. Bodea, M.A. Steiger, W. Markowitsch, W. Lang. Phys. Procedia 36, 508 (2012).

[14] C.A. Lang, M. Marksteiner, M.A. Bodea. Nucl. Instrum. Meth. Phys. Res. B 272, 300 (2012).

[15] В.К. Васильев, Д.С. Королев, С.А. Королев. Труды ХІХ Междунар. симпозиума „Нанофизика и наноэлектроника“. Нижний Новгород, (2015). С. 79.

[16] Д.В. Мастеров, С.А. Павлов, А.Е. Парафин, П.А. Юнин. Письма в ЖТФ 42, 82 (2016). 
[17] Ю.Н. Дроздов, Д.В. Мастеров, С.А. Павлов, А.Е. Парафин, П.А. Юнин. ЖТФ 85, 109 (2015).

[18] A.M. Klushin, M. He, S.L. Yan, N. Klein. Appl. Phys. Lett. 89, 232505 (2006).

[19] Y. Tanaka, S. Kashiwaya. Phys. Rev. B 56, 892 (1997).

[20] А. Бароне, Дж. Патерно. Эффект Джозефсона. Физика и применения. Мир, М. (1984). 640 с.

[21] К.К. Лихарев, Б.Т. Ульрих. Системы с джозефсоновскими контактами. Изд-во МГУ, М. (1978).

[22] B. Hu, J. Tekić. Appl. Phys. Lett. 90, 102119 (2007).

[23] Y. Ota, M. Machida, T. Koyama. Phys. Rev. B 82, 140509 (2010).

[24] A.A. Golubov, M.Yu. Kupriyanov, E. Ilichev, Rev. Mod. Phys. 76, 411 (2004). 